\title{
Trânsito com vida: um portal na Web
}

\author{
E. O. Faria ${ }^{1}$
}

Secretaria Municipal de Transportes do Rio de Janeiro, Brasil

M. G. C. Braga ${ }^{2}$

Universidade Federal do Rio de Janeiro, Brasil

G. H. B. Campos ${ }^{3}$

Pontifícia Universidade Católica, Rio de Janeiro, Brasil

RESUMO: Este artigo apresenta o Portal na Web "Trânsito Com Vida", desenvolvido a partir de diretrizes estabelecidas por metodologia fundamentada em: critérios técnico-pedagógicos para elaboração e avaliação de softwares educativos; pesquisa bibliográfica; pesquisa com especialistas e com 400 alunos do Ensino Fundamental. O Portal foi fundamentado nas abordagens Construtivista, Sociocultural e Holística, com o objetivo de tornar o aluno ativo em seu processo de construção do conhecimento, desenvolver seu potencial de reflexão crítica e possibilitar a vivência da solidariedade e da cooperação. O Portal é dirigido a crianças, adolescentes e professores de $5^{\text {a a }} 8^{\text {a }}$ séries do Ensino Fundamental, com interface gráfica e educacional diferenciadas, incluindo estratégias educacionais, animação digital, jogo de simulação e uma ferramenta de comunicação assíncrona em um Fórum para Discussão. Um grupo de professores, utilizando critérios pedagógicos e técnicos, avaliou o Portal quanto à navegabilidade, à compreensão do conteúdo, da proposta educacional e da filosofia subjacente.

ABSTRACT: This paper aims at presenting the Portal on the Web named "Traffic With Life". Its development was based on: technical and teaching-learning criteria for building and evaluating educational software; literature review; survey with traffic safety professionals; survey with 400 students from Basic School Grades. The Constructivist, Socio-Cultural and Holistic approaches were used aiming at: ensuring that students are active in the process of knowledge building; developing their potential for judicious appraisal; giving students the opportunity to experience solidarity and cooperation. The Portal is directed to children, adolescents and teachers from 5th to 8th Grades of Basic School and uses different graphic and educational interfaces for each group. It includes teaching and learning strategies, digital animation, simulation game and an asynchronous tool for communication within a Discussion Forum. A group of teachers evaluated the Portal using pedagogic and technical criteria. They evaluated features such as navegability and apprehension of the contents, of the educational proposal and its underlying philosophy.

\section{INTRODUÇÃO}

A situação do trânsito atual é reflexo das relações que estabelecemos na sociedade. A competição e o individualismo têm gerado sentimentos de medo ou raiva: a proximidade de um outro cidadão (motorista, pedestre etc.), compartilhando o mesmo espaço urbano, é percebida como ameaça ou obstáculo. A violência no trânsito é uma tragédia social, que ceifa vidas e esperanças de muitos brasileiros. Toda a sociedade deve se esforçar para minimizar este vergonhoso quadro, que coloca o Brasil como um dos campeões mundiais da violência no trânsito. Quase todos os países que conseguiram vencer a batalha contra as mortes no trânsito, contaram com a participação de toda a sociedade: governo, comunidade e iniciativa privada.

Um dos instrumentos que pode colaborar decisivamente para a redução do problema é a Educação para o Trânsito. Sabendo desta ação, a sociedade brasileira e os legisladores elaboraram o Código de Trânsito Brasileiro, tornando obrigatório o ensino de temas relacionados ao trânsito, a partir de 1999, em todas as escolas, públicas ou particulares, do pré-escolar ao $3^{\circ}$ grau.

O reconhecimento da importância do elemento humano enquanto fator contribuinte para a ocorrência dos acidentes de trânsito e da necessidade de um processo educativo que modifique este comportamento de risco é um dos objetivos das campanhas educativas que pretendem atingir os cidadãos adultos.

Quanto às crianças e adolescentes, alguns trabalhos estão direcionados para aspectos da sua formação nas escolas. São desenvolvidos de acordo com abordagens pedagógicas comportamentais e cognitivistas. Esta prática acredita que o ensino das regras de trânsito e das conseqüências legais da sua inobservância sejam suficientes para modelar o 
comportamento dos alunos. Segundo a Organização de Cooperação para o Desenvolvimento Econômico (OCDE, 1986), esta prática nem sempre resulta na formação de comportamentos esperados. Em geral, são os técnicos/adultos que identificam os conceitos e aspectos a serem abordados no aprendizado, bem como produzem os instrumentos necessários para tanto. A crítica fundamental a este procedimento é que o ponto de vista infantil, sua percepção e sua expectativa não são pesquisados suficientemente, nem tampouco levados em consideração.

Desta forma, conscientes da necessidade de se produzir um material de qualidade sobre o tema, este artigo apresenta o desenvolvimento de um ambiente de aprendizagem interativo, elaborado a partir de critérios técnico-pedagógicos para o desenvolvimento de softwares educacionais (Campos, 1994; Reeves e Hedberg, 2003) e de uma ampla pesquisa bibliográfica sobre a Educação para o Trânsito e de pesquisas com especialistas brasileiros e com estudantes do Ensino Fundamental (Faria, 2002).

\section{EDUCAÇÃO PARA O TRÂNSITO}

$\mathrm{Na}$ revisão bibliográfica de Faria (2002), foram identificados dois paradigmas da Educação para o Trânsito (ET). O primeiro, o tradicional, tem como meta reduzir o número e a gravidade dos acidentes, através da mudança do comportamento do indivíduo, de modo a adaptá-lo à tecnologia do automóvel, e do treinamento de habilidades para protegê-lo do perigo das vias. O segundo, o novo paradigma, tem como meta reduzir os riscos presentes nas vias, promovendo o questionamento da forma predominante da circulação de veículos, do uso de carros particulares, da poluição sonora e atmosférica, contribuindo, desta forma, para a mudança de normas sociais e estilos de vida da sociedade.

Segundo Faria (2002), em geral, a prática educativa para o trânsito no Brasil e no exterior segue o paradigma tradicional. Para desenvolver programas e produzir materiais educativos para crianças e adolescentes, salvo raras exceções como Clayton et al. (1995), a prática nacional e internacional adota uma concepção também tradicional, na qual os técnicos/ adultos identificam os conceitos e aspectos do tema. No Brasil, em particular, as atividades são esporádicas e desenvolvidas sem aprofundar os temas, utilizam a competição para estimular a participação e repetem experiências estrangeiras sem os estudos necessários para adaptá-las à nossa realidade. Por abordar o tema somente de forma cognitiva, nem sempre conseguem atingir seus objetivos (OCDE, 1986).

Foram encontradas algumas páginas na web sobre Educação para o Trânsito voltadas para pais e professores, como as de Departamentos de Trânsito
Estaduais (Paraná, 2004; Ceará, 2004) e de instituições (SENAC, 2004). Em geral, abordam o tema apenas como transmissão de conteúdos, enfatizando o cumprimento e o conhecimento das regras de circulação: os cuidados ao atravessar a rua e na saída da escola, no ônibus escolar, no carro de seus pais e de bicicleta. Raramente incentivam a crítica ou propõem debates sobre o tema. Foram encontradas apenas duas páginas voltadas para crianças e adolescentes (Canal Kids, 2004; Instituto Cultural Maurício de Souza, 2004), que pretendem atingir o público com mensagens bem-humoradas e instigantes, mas somente com o enfoque na prevenção de acidentes.

\section{METODOLOGIA}

A metodologia utilizada para a elaboração do Portal proposto foi desenvolvida por Faria (2002), fundamentada em critérios técnico-pedagógicos a partir de Campos (1994) e Reeves e Hedberg (2003) e em duas pesquisas, resumidas a seguir: pesquisas com especialistas brasileiros e com estudantes do Ensino Fundamental.

\subsection{Novas tecnologias em educação}

Segundo Faria e Braga (1999), "através de softwares educacionais e de seus recursos audiovisuais de extrema utilidade, o computador pode permitir a manipulação das inúmeras variáveis que participam do complexo ambiente do trânsito urbano". Com estas ferramentas, é possível conseguir uma atuação mais participativa do aluno, devido à atração natural que tem em relação ao computador e à navegação na Internet. A análise dos problemas do trânsito e o uso de novas tecnologias como recurso pedagógico são fatores que servem para integrar a escola e o mundo. Podem permitir a transmissão de conhecimentos e o desenvolvimento de habilidades e de atitudes para que o aluno atue em busca de melhor qualidade de vida, num ambiente condizente com suas necessidades e aspirações.

Um software educacional deve ser desenvolvido para atender a objetivos educacionais preestabelecidos, no qual a técnica se subordina às considerações de ordem pedagógica que orientam seu desenvolvimento. Um produto de software para a área educacional deve trabalhar com motivos que atinjam diretamente o público alvo e com dados reais. Um software educacional possui critérios técnicos e pedagógicos que, de acordo com Campos (1994), podem ser resumidos como a seguir:

(a) propiciar meios para a resolução dos conflitos sócio-cognitivos entre os diversos componentes;

(b) ser concebido por uma teoria que aborde o aspecto social da interação homem-máquina; 
(c) facilitar as atividades cognitivas coletivas, sob diversas formas, explorações, tomadas de decisão, participação na validação de respostas, entre outras;

(d) apresentar inúmeras alternativas para desafiar a interação dos indivíduos, de modo a sustentar um continuado equacionamento de variáveis, a construção cooperativa de hipóteses e a resolução coletiva de problemas.

\subsection{Pesquisa com especialistas em educação para o trânsito}

Para identificar os objetivos de uma educação de crianças e adolescentes para o trânsito mais adequados à realidade brasileira e quais as condições necessárias para garantir o sucesso dessas ações educativas, Faria e Braga (2004) entrevistaram 65 especialistas brasileiros, que propuseram a revisão do paradigma tradicional, "pois consideraram que as ações educativas teriam elevada efetividade se no seu planejamento fossem considerados o ponto de vista, a percepção e a expectativa das crianças sobre o trânsito urbano, tornando o aluno ativo em seu processo de ensino/aprendizagem. Neste sentido, se ao aluno não for permitido refletir criticamente sobre o trânsito, sobre as conseqüências da liberdade do automóvel no sistema viário e se ele não puder vivenciar os valores solidariedade e cooperação nas aulas e em situações reais do trânsito, as ações educativas não estarão contribuindo para a formação de um cidadão, nem de um motorista que respeite as regras por compreendê-las como condição fundamental para a vida em sociedade". Os especialistas entrevistados "acreditam que além de objetivar a redução do número e da gravidade dos acidentes, a ET deve propor a redução dos riscos no trânsito, por meio da mudança de normas sociais e de estilos de vida, pois a ET deve levar em conta os valores, atitudes e comportamentos adquiridos na família e no convívio social. Desta forma, os entrevistados sugeriram a reformulação das metodologias educacionais atuais, baseadas unicamente na transmissão de conteúdos, para metodologias que partam de uma visão crítica dos padrões atuais de saber e de convivência" (Faria e Braga, 2004).

\subsection{Pesquisa de percepção com crianças e adolescentes}

Para identificar a percepção do público alvo das ações educativas, Faria (2002) entrevistou 400 alunos da $4^{\text {a }}$ à $8^{\text {a }}$ séries do Ensino Fundamental de 5 escolas públicas e de 5 escolas particulares do município do Rio de Janeiro, que elaboraram redações narrando situações perigosas ou acidentes e propondo soluções para melhorar a segurança do trânsito. Estas redações foram analisadas com o auxílio da técnica "Análise do Discurso" para identificar e analisar seus princípios argumentativos, chamados “topoï” (Anscombre e Ducrot, 1983). No total, 109 "topoï” foram identificados.

Em seus textos, os estudantes demonstraram estar conscientes dos riscos diários no trânsito, identificaram no comportamento e no poder do motorista sobre o pedestre o principal responsável pelos acidentes e solicitaram ações urgentes dos governantes, enfatizando soluções de Engenharia e de Fiscalização. Os alunos consideraram que o acidente é uma tragédia. Sentiram-se ameaçados pelo automóvel, classificando, por vezes, de "irresponsável" o motorista que desrespeita as regras e, de "monstruoso e cruel", aquele que não socorre sua vítima. Qualificaram o governo de "incompetente e irresponsável" e consideraram a impunidade como um importante fator contribuinte para o desrespeito às regras e para a ocorrência de acidentes.

Faria (2002) conclui que a vivência diária nas ruas pode ter originado a consciência e a indignação demonstradas pelos alunos a respeito das situações de risco no trânsito. "Isto mostra a necessidade e a oportunidade de ações educativas mais participativas, em que o público reflita sobre o tema, desenvolva sua cidadania, seja sensibilizado para a necessidade de atitudes cooperativas, apresente propostas e se engaje na tarefa de melhorar o trânsito" (Faria, 2002).

Este conjunto de pesquisas possibilitou rever a prática da ET e propor a adoção de abordagens pedagógicas reconhecidas internacionalmente pelo termo "educação ativa", de modo que se consiga inserir o tema em um contexto mais amplo e atingir a principal meta da segurança de tráfego: a redução dos riscos presentes nas vias.

\section{RESULTADOS}

As diretrizes estabelecidas no item anterior serviram para fundamentar o desenvolvimento do Portal para Web "Trânsito ComVida", atualmente em fase final de testes e que pode ser acessado nos endereços www.transitocomvida.ufrj.br ou www.base.pro. br/sites/educt.

\subsection{Concepção pedagógica}

Na Educação para o Trânsito atualmente aplicada nas escolas, é comum os alunos receberem os conteúdos a partir de conceitos abstratos, de modo teórico e desvinculados de sua realidade. No Portal, os conteúdos deixam de ser um fim em si mesmos 
e passam a ser meios para ampliar a formação dos alunos e sua interação com o mundo em que vivem, de forma crítica e dinâmica. Há o rompimento com a concepção de "neutralidade" do tema trabalhado, que passa a ganhar significados diversos, a partir das experiências sociais dos alunos.

A concepção pedagógica do Portal está fundamentada na combinação das abordagens construtivista (Piaget, 1973), sociocultural (Freire, 1978) e holística (Weil, 1990). Estas abordagens permitem que o aluno construa conhecimento (construtivista) e desenvolva habilidades a partir da reflexão sobre sua real situação no trânsito e sobre a liberdade do automóvel no sistema viário (sociocultural), bem como possibilitam que ele vivencie valores fundamentais para se conseguir um trânsito mais humano, a solidariedade e a cooperação (holística).

Esta concepção enfatiza que o aluno deixe de apenas memorizar as regras de trânsito para formarse como sujeito atuante na sociedade em que vive. Busca-se a formação global dos alunos, objetivando não somente a redução dos acidentes, mas a redução dos riscos presentes nas vias.

Uma ET em concordância com os preceitos aqui descritos apresenta uma possibilidade de intervir na violência do trânsito, procurando desenvolver atitudes geradoras de melhor qualidade de vida e mais segurança. Com o tema trânsito, há múltiplas possibilidades para o professor exemplificar o valor de uma relação cooperativa. Ele deverá, porém, sempre estender esta relação para todas as áreas. Broto (1997) sugere várias atividades cooperativas aplicáveis à ET e cita Orlick para fazer um paralelo entre jogos cooperativos e competitivos, conforme mostra a Tabela 1.

\subsection{O Portal}

Os principais temas e conteúdos do Portal são: o processo histórico de evolução da cidade e suas conseqüências no transporte e na violência do trânsito; a formação ética, solidária e cidadã na melhoria do trânsito; os comportamentos seguros para pedestres, ciclistas, motoristas e passageiros; as conseqüências dos comportamentos inadequados no trânsito; a sensação de onipotência do jovem e suas conseqüências no trânsito; os riscos associados ao excesso de velocidade, ao uso de bebida alcoólica e ao não uso do capacete ou do cinto de segurança; o excesso de velocidade e o prazer de dirigir; as dificuldades de cada faixa etária para enfrentar o trânsito urbano atual; os aspectos físicos e de comportamento das crianças e dos adolescentes; a evolução da capacidade de avaliar os riscos.

O Portal é dirigido a crianças, adolescentes, professores e a todos aqueles que se interessam pelo trabalho relacionado à área. O Portal oferece material para o professor e material para os alunos com a interface gráfica e educacional diferenciadas, jogos e uma discussão que envolve quatro contextos de aprendizagem (Riscos no trânsito; Transporte e qualidade de vida; Ética e cidadania; Evolução dos Transportes), além de ferramentas como um Fórum para Discussão. A seguir, são mostrados os principais recursos do Portal.

\subsubsection{Principais telas e acessos}

$\mathrm{Na}$ primeira tela do Portal (Figura 1) podem ser vistos seus principais acessos, além dos ícones que possibilitam acessar as interfaces do Aluno e do Professor. Outros ícones apresentados são os seguintes: Dicas e Curiosidades; A concepção pedagógica do Portal; Como utilizar?; Bibliografia utilizada para a implementação do Portal; Créditos; Acesso para

Tabela 1: Paralelo entre jogos competitivos e cooperativos

\begin{tabular}{l|l}
\hline \multicolumn{1}{c|}{ JOGOS COMPETITIVOS } & \multicolumn{1}{c}{ JOGOS COOPERATIVOS } \\
\hline São divertidos apenas para alguns & São divertidos para todos \\
\hline A maioria tem um sentimento de derrota & Todos têm um sentimento de vitória \\
\hline Alguns são excluídos por sua falta de habilidade & $\begin{array}{l}\text { Há mistura de grupos que brincam juntos, criando alto } \\
\text { nível de aceitação mútua }\end{array}$ \\
\hline Aprende-se a ser desconfiado & Todos participam e ninguém é rejeitado ou excluído \\
\hline $\begin{array}{l}\text { Os perdedores ficam de fora do jogo e simplesmente se } \\
\text { tornam observadores }\end{array}$ & $\begin{array}{l}\text { Os jogadores aprendem a ter um senso de unidade e a } \\
\text { compartilhar o sucesso }\end{array}$ \\
\hline $\begin{array}{l}\text { Os jogadores não se solidarizam e ficam felizes quando } \\
\text { alguma coisa "ruim" acontece aos outros }\end{array}$ & $\begin{array}{l}\text { Desenvolvem autoconfiança, porque todos são bem } \\
\text { aceitos }\end{array}$ \\
\hline $\begin{array}{l}\text { A pouca tolerância à derrota desenvolve em alguns } \\
\text { jogadores um sentimento de desistência face às dificuldades }\end{array}$ & $\begin{array}{l}\text { A habilidade de perseverar face às dificuldades é } \\
\text { fortalecida }\end{array}$ \\
\hline Poucos se tornam bem sucedidos & Para cada um, o jogo é um caminho de co-evolução \\
\hline
\end{tabular}




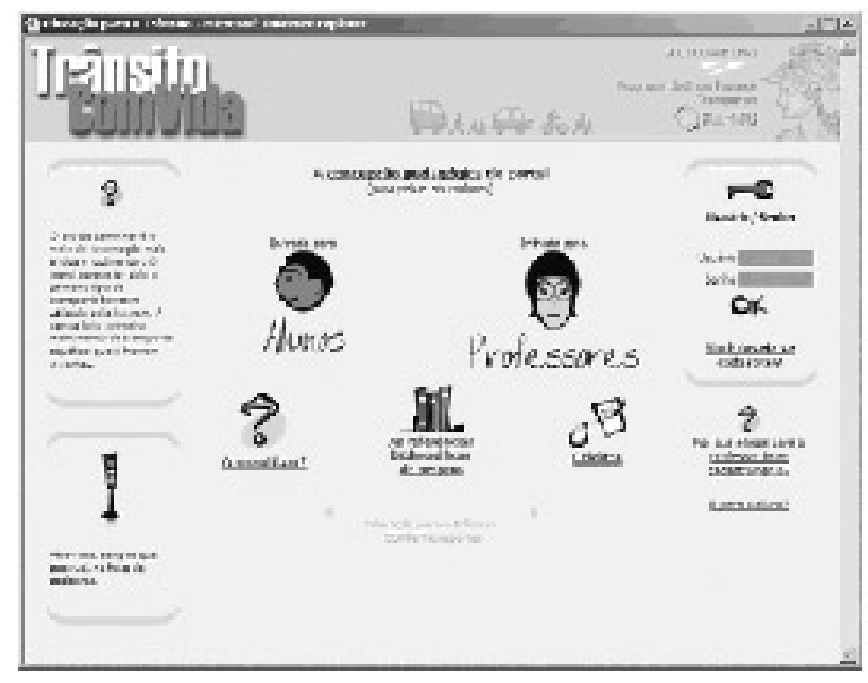

Figura 1: Tela inicial do Portal

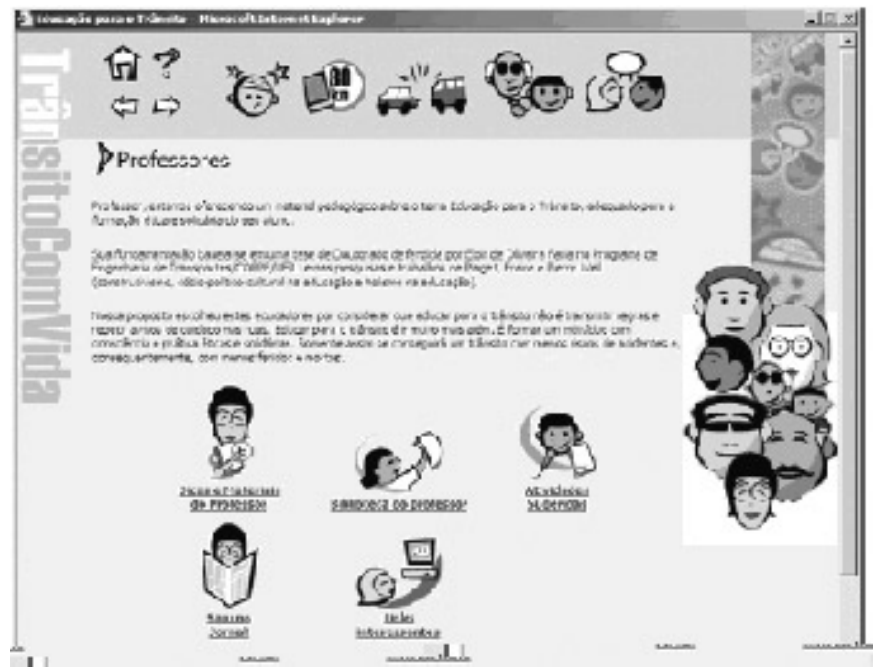

Figura 3: Primeira tela da interface do professor

usuários cadastrados; Instruções para o cadastramento de usuários novos.

A interface do aluno (Figura 2) direciona o aluno para diferentes possibilidades de estudo e trabalho como descrito a seguir:

a) Situações para análise, que são filmes de desenho animado ou histórias em quadrinhos, onde são mostradas situações de risco de atropelamento;

b) Simulação de uma rua, onde poderá propor soluções para as situações de atropelamento;

c) Textos sobre a história do transporte;

? d) Jogo para teste de conhecimentos sobre placas e sinalização do trânsito;

e) Notícias de jornais sobre Educação para o Trânsito;

f) "Links" interessantes;

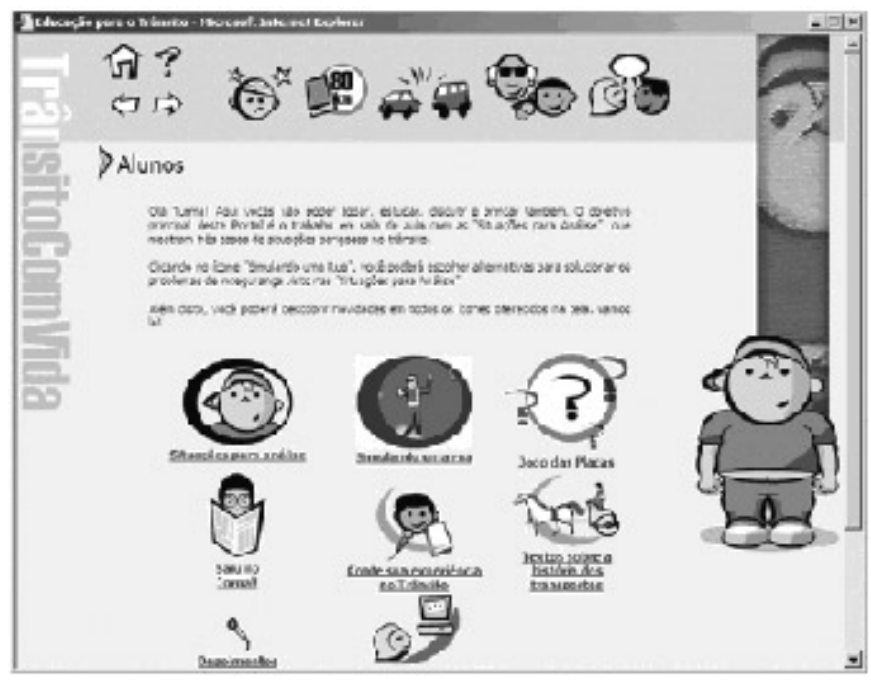

Figura 2: Primeira tela da interface do aluno

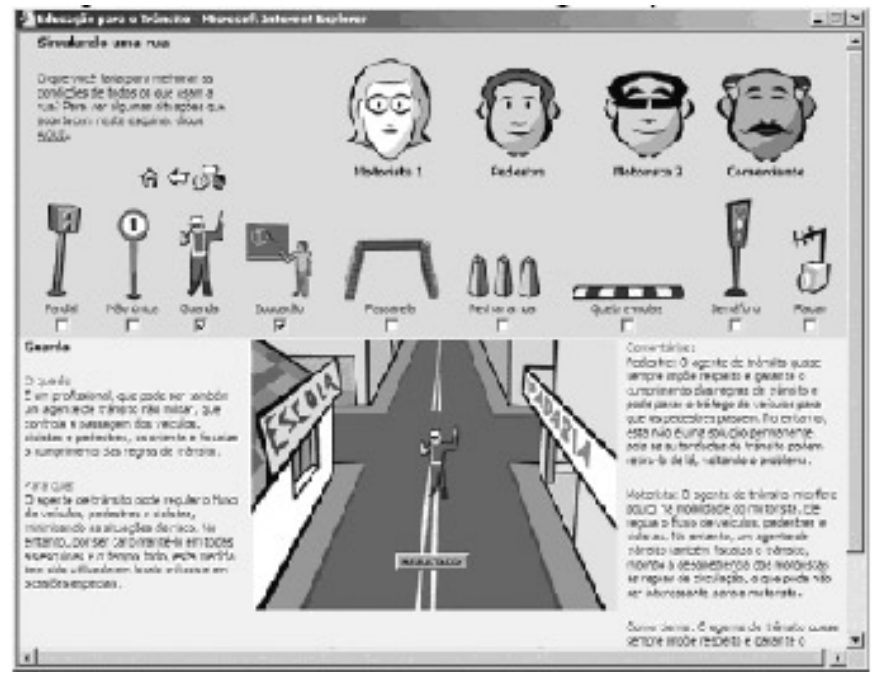

Figura 4: Tela da Simulação

g) "Depoimentos" de alunos que vivenciaram situações de risco ou acidentes;

h) "Conte sua experiência no trânsito", onde o aluno poderá contar sua vivência no trânsito.

A idéia pedagógica subjacente ao desenho animado ou à história em quadrinhos das "Situações para Análise", bem como à simulação, é gerar situações de aprendizagem a partir de discussões em sala de aula. Os alunos e o professor deverão consultar os textos disponibilizados nas bases de dados mostradas a seguir:

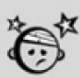

a) Riscos no trânsito, onde são encontrados textos sobre as dificuldades, os riscos e as medidas adequadas às pessoas que circulam nas vias em área rural e urbana.

b) Código de Trânsito Brasileiro, texto da lei comentado; 
c) Ética e Cidadania, onde são encontrados textos sobre estes temas;

d) Nesta base de dados, estão textos sobre Transporte e Qualidade de vida.

e) Os alunos deverão responder a questões propostas inicialmente pelo professor no Fórum de Discussão, onde a idéia está representada como "Converse com os colegas".

A interface do professor (Figura 3 ) dá acesso às mesmas bases de dados e possui os mesmos símbolos da interface do aluno. Possui ainda novas sessões, diferentes da interface do aluno, direcionadas ao apoio as atividades em sala de aula. Os novos ícones, direcionados apenas para o professor, são:

a) Em "Dicas e Materiais do Professor", existem explicações sobre a utilização do Portal e também orientação para o trabalho com os alunos;

b) $\mathrm{Na}$ sessão "Biblioteca do Professor", existem textos para subsidiar suas aulas;

c) Na sessão "Atividades Sugeridas", o professor encontra materiais e estratégias para sua aula.

\subsubsection{Software de Simulação "Simulando uma rua"}

Este software foi desenvolvido inicialmente para CD-ROM com apoio do $\mathrm{CNPq}$, mas foi redesenhado para a Internet (Figura 4). Como a estratégia pedagógica do Portal é voltada para a relação entre os alunos, antes de propor o uso da simulação, o professor é orientado a utilizar filmes e histórias em quadrinhos das "Situações para análise". Os alunos vêem os três filmes ou histórias em quadrinhos das situações de risco de atropelamento e discutem sobre as situações, utilizando a seguinte técnica proposta na simulação: dividem-se em quatro grupos e escolhem um dos personagens para representar (Pedestre; Motorista 1, que mora nas redondezas; Motorista 2, que utiliza a via como passagem; Comerciante local). Estes personagens têm interesses conflitantes: acessibilidade, segurança e fluidez, conforme Faria e Braga (1999). Os alunos representam os papéis destes quatro tipos de personagens, defendendo seus interesses na discussão sobre os problemas de segurança no trânsito vistos nos filmes. Os alunos declaram sua visão sobre o problema apresentado na sessão "Fórum de discussão".

Após esta etapa inicial, cada aluno/personagem escolhe um conjunto de alternativas para solucionar os problemas mostrados nos filmes, acessando a sessão "Simulando uma rua". Depois, discutem no grupo de alunos/personagens sua alternativa, defendendo seus interesses e consultando os textos do Código de Trânsito Brasileiro e das bases de dados de Riscos no Trânsito, Transporte e Qualidade de Vida e Ética e Cidadania. Para concluir o uso da ferramenta, os alunos/personagens discutem e escolhem um conjunto de alternativas que seja resultante do acordo entre eles. Havendo consenso ou não, o conjunto de alternativas escolhido é colocado no Fórum de Discussão e pode ser impresso.

É recomendável que cada aluno participe das atividades mais de uma vez, vivenciando os quatro tipos de personagem. Isto é muito importante para que sejam atingidos os seguintes objetivos: perceber a complexidade do tema, desenvolver a empatia e verificar que, na sua experiência pessoal, ele também deseja fluidez, acessibilidade e segurança.

\subsection{Avaliação do Portal}

O Portal foi avaliado por 35 alunos de um curso de pós-graduação "lato sensu" no Magistério Superior, em uma cidade da região serrana do Estado do Rio de Janeiro, que estavam cursando a disciplina chamada "Educação baseada na Web". O grupo de alunos é constituído por professores do Ensino Fundamental, do Ensino Médio, do Ensino Superior, de cursos profissionalizantes e por profissionais liberais (médicos e dentistas). O objetivo do teste foi verificar a navegação do Portal e a compreensão do conteúdo, sob o ponto de vista do professor, utilizando os seguintes procedimentos: painel com professores e preenchimento de uma ficha com critérios avaliativos propostos por Reeves e Hedberg (2003).

O método proposto por Reeves e Hedberg (2003) apresenta duas abordagens complementares na avaliação qualitativa de software educacional. A primeira baseia-se em quatorze critérios pedagógicos e a segunda, em dez critérios relacionados à interface com o usuário. A avaliação ocorre por meio do preenchimento de uma ficha, onde o professor assinala uma marca sobre um gráfico representado por uma seta dupla. Em cada extremidade da seta, são colocados os conceitos antagônicos que caracterizam o critério. A extremidade direita foi definida de modo a retratar a concepção pedagógica que norteou a construção do Portal e de seus conteúdos. A extremidade esquerda foi definida em contraposição à anterior e com base na melhor formulação encontrada que expressasse o conceito antagônico.

Mostra-se na Figura 5 a média da avaliação dos professores para os quatorze critérios pedagógicos que compõem a primeira abordagem, definidos a seguir:

- Epistemologia: de Objetivista (o conhecimento é adquirido de forma objetiva através dos sentidos; a aprendizagem consiste em adquirir verdades) 


\begin{tabular}{|c|c|c|c|}
\hline Epistemologia & Objetivista & & Construtivista \\
\hline Filosofia Pedagógica & Instrutivista & & Construtivista \\
\hline Psicologia Subjacente & Comportamental & & Cognitiva \\
\hline Objetividade & Precisamente Focalizado & & Não-focalizado \\
\hline Seqüenciamento Instrucional & Reducionista & & Construtivista \\
\hline Validade Experimental & Abstrato & & Concreto \\
\hline Papel do instrutor & Provedor de Materiais & & Agente Facilitador \\
\hline Valorização do Erro & Aprendizado sem erro & & \begin{tabular}{|l|} 
Aprendizado com \\
a experiência
\end{tabular} \\
\hline Motivação & Extrínseca & & Intrínseca \\
\hline Estruturação & Alta & & Baixa \\
\hline Acomodação de Diferenças Individuais & Não existente & 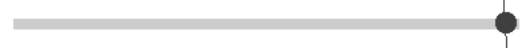 & Multi-facetada \\
\hline Controle do Aluno & Não existente & & Irrestrito \\
\hline Atividade do Usuário & Matemagênico & & Generativo \\
\hline Aprendizado Cooperativo & Não-suportado & & Integral \\
\hline
\end{tabular}

Figura 5: Avaliação do portal "Trânsito com vida" utilizando os 14 critérios pedagógicos do método para avaliação de software educacional de Reeves e Hedberg (2003)

a Construtivista (o conhecimento da realidade é individualmente construído; o conhecimento é construído subjetivamente com base em experiências anteriores e em um processo metacognitivo ou reflexão);

- Filosofia Pedagógica: de Instrutivista (enfatiza a importância de metas e objetivos independentes do aluno; com base na teoria comportamentalista; o aluno é visto como um agente passivo) a Construtivista (enfatiza a primazia da intenção, experiência e estratégias metacognitivas do aluno: o aluno é visto como um indivíduo repleto de conhecimento preexistente, atitudes e motivações);

- Psicologia Subjacente: de Comportamental (os fatores do aprendizado não são comportamentos que podem ser diretamente observados; a instrução consiste na modelagem do comportamento desejável obtido através de estímulo-respostas) a Cognitiva (dá ênfase aos estados mentais internos ao invés do comportamento psicológico; reconhece que uma ampla variedade de estratégias de aprendizagem deve ser empregada, considerando o tipo de conhecimento a ser construído);

- Objetividade: de Precisamente Focalizado (forma empregada em tutoriais e treinamentos) a Nãofocalizado (forma empregada nos micro-mundos, simulações virtuais e ambientes de aprendizado);
- Seqüenciamento Instrucional: de Reducionista (o aprendizado sobre determinado conteúdo requer que todos os seus componentes sejam previamente entendidos) a Construtivista (o aluno é colocado em um contexto realístico, o qual irá requerer soluções de problemas; o apoio é introduzido de acordo com a necessidade individual do aluno);

- Validade Experimental: de Abstrato (utiliza situações que não pertencem ao mundo real do aluno) a Concreto (se preocupa em sempre contextualizar o conteúdo apresentado situações da realidade);

- Papel do instrutor: de Provedor de Materiais (o programa instrutor é considerado "o dono do conhecimento") a Agente Facilitador (o programa instrutor é visto como uma fonte de orientação e consulta);

- Valorização do Erro: de Aprendizado sem erro (as instruções são organizadas de maneira que o aluno é induzido a responder corretamente) a Aprendizado com a experiência (apoia-se na máxima "a experiência é o melhor professor"; provê oportunidades para que o aluno aprenda com seus próprios erros);

- Motivação: de Extrínseca (a motivação vem de fora do ambiente de aprendizado) a Intrínseca (integrada ao ambiente de aprendizado); 
- Estruturação: de Alta (os caminhos são previamente determinados) a Baixa (uma série de opções é oferecida de modo que o aluno possa escolher a ordem que desejar);

- Acomodação de Diferenças Individuais: de Não existente (considera os indivíduos iguais, homogêneos) a Multi-facetada (leva em consideração a diferença entre os indivíduos);

- Controle do Aluno: de Não existente (todo o controle pertence ao programa) a Irrestrito (o aluno decide que sessões estudar, que caminhos seguir, que material utilizar);

- Atividade do Usuário: de Matemagênico (ambientes de aprendizagem, nos quais pretende-se capacitar o aluno a "acessar" várias representações do conteúdo) a Generativo (ambientes de aprendizagem que engajam o aluno no processo de criação, elaboração ou representação do conteúdo);

- Aprendizado Cooperativo: de Não-suportado (não permite o trabalho cooperativo entre alunos - em pares ou grupos) a Integral (permite o trabalho cooperativo de modo que os objetivos sejam compartilhados, beneficiando o aluno tanto instrucionalmente quanto socialmente).

Mostra-se na Figura 6 a média da avaliação dos professores para os dez critérios relacionados à interface com o usuário, definidos a seguir:

- Facilidade de Utilização: de Difícil a Fácil;

- Navegação: de Difícil a Fácil;

- Carga Cognitiva: de Não Gerenciável/Confusa a Gerenciável/Intuitiva;

- Mapeamento: (se refere à habilidade do programa em rastrear os caminhos percorridos pelo aluno) de Nenhum a Poderoso;
- "Design" de Tela: de Princípios Violados a Princípios Respeitados;

- Compatibilidade Espacial do Conhecimento: de Incompatível a Compatível;

- Apresentação da Informação: de Confusa a Clara;

- Integração das Mídias: de Não Coordenada a Coordenada;

- Estética: de Desagradável a Agradável;

- Funcionalidade Geral: de Não Funcional a Altamente Funcional.

Com base na opinião destes professores, há indicação de que eles qualificaram positivamente o protótipo do Portal para a maioria dos critérios propostos. Este primeiro experimento de avaliação permite identificar alguns aspectos que merecem ser analisados em maior detalhe pela equipe que desenvolveu o Portal. Por exemplo, os aspectos relacionados a "Motivação", "Atividade dos Usuários", "Aprendizado Cooperativo" e "Mapeamento" devem ser verificados antes de ser realizada nova avaliação, incorporando possíveis ajustes ao Portal na sua forma atual, especificamente com relação a estas características.

Mesmo utilizando um método de avaliação que não permite quantificação, a compreensão da proposta educacional e a filosofia subjacente ao produto avaliado apontaram para a exeqüibilidade da proposta defendida neste trabalho. Futuramente, uma avaliação quantitativa deve ser realizada, adaptando o método proposto por Reeves e Hedberg (2003), de modo a identificar, com maior precisão, possíveis diferenças entre a proposta do Portal (já incorporando os ajustes decorrentes da avaliação aqui mostrada) e a opinião dos novos entrevistados, para cada critério anteriormente apontado.

\begin{tabular}{|l|c|l|l|}
\hline Facilidade de Utilização & Difícil & Difícil & Fácil \\
\hline Navegação & Não gerenciável/confusa & Nenhum & Fácil \\
\hline Carga Cognitiva & Princípios violados & Gerenciável/intuitiva \\
\hline Mapeamento & Incompatível & Poderoso \\
\hline “Design” de Tela & Nompano coordenada & Princípios respeitados \\
\hline Apresentação da Informação & Desagradável & Compatível \\
\hline Integração das Mídias & Não funcional & Clara \\
\hline Estética & & Coordenada \\
\hline Funcionalidade Geral & Agradável & Altamente Funcional \\
\hline
\end{tabular}

Figura 6: Avaliação do portal "Trânsito com vida" utilizando os 10 critérios relacionados à interface com o usuário do método para avaliação de software educacional de Reeves e Hedberg (2003) 


\section{CONCLUSÃO}

Este artigo apresentou o Portal na Web "Trânsito Com Vida", desenvolvido principalmente a partir de pesquisa que identificou a percepção de crianças e adolescentes sobre o trânsito, que retrataram sua perplexidade quando se defrontam com a violência do ambiente real do trânsito.

A concepção pedagógica adotada no Portal, fundamentada nas abordagens Construtivista, Sociocultural e Holística, tem as seguintes características, que a diferencia das demais: não ignora o sofrimento e a opressão dos alunos no trânsito; sensibiliza para atitudes não fragmentadas no trânsito e na vida; sensibiliza para que os alunos, quando adultos, não reproduzam a opressão à qual foram expostos no trânsito; permite o desenvolvimento de ações educativas durante todo o ano letivo dentro da grade curricular, sob o enfoque da transversalidade.

O Portal na Web "Trânsito ComVida" foi avaliado positivamente por um grupo de professores, que compreendeu sua proposta educacional e filosofia subjacente. Uma avaliação que incorpore análise quantitativa deve ser feita numa próxima etapa, adaptando a metodologia proposta por Reeves e Hedberg (2003).

Professor e aluno devem compartilhar experiências e sentimentos, dividir temores, indignação e esperanças, experimentar sensações de empatia com aqueles que sofreram com a violência no trânsito, a partir dos relatos das opressões sofridas. Ao desenvolverem essa empatia, o aluno não deve reproduzir o papel de opressor no futuro, quando for um motorista.

Assim, espera-se que as propostas e conceitos aqui defendidos permitam o desenvolvimento de habilidades e atitudes para que o homem influa no processo de melhoria de sua qualidade de vida, bem como contribuam para a formação e a consolidação de valores compatíveis com um trânsito mais humano.

\section{Agradecimentos}

Os autores agradecem ao Conselho Nacional de Pesquisa (CNPq) e à Fundação de Amparo à Pesquisa do Estado do Rio de Janeiro (FAPERJ), que viabilizaram, respectivamente, o desenvolvimento do software de Simulação "Trânsito e Cidadania" e do Portal para Web "Trânsito ComVida".

\section{REFERÊNCIAS}

Anscombre, J-C. e O. Ducrot (1983) L'Argumentation dans la langue. Mardaga, Bruxelas.

Broto F. O. (1997) Jogos cooperativos: se o importante é competir, o fundamental é cooperar! Projeto Cooperação, Santos, SP.
Campos, G. H. B. (1994) Metodologia para avaliação da qualidade de software educacional: diretrizes para desenvolvedores e usuários. Tese de D.Sc., COPPE/UFRJ, Rio de Janeiro, RJ, Brasil.

Canal Kids (2004) Disponível em < http://www.canalkids.com. br/cidadania/transito $>$ Acesso em 11 jun. 2004.

Ceará (2004) Disponível em <http://www.detran.ce.gov.br/ educacao $>$ Acesso em 11 jun. 2004.

Clayton, A . B.; C.V. Platt; M. A. Colgan e G. Butler (1995) A child based approach to road safety education for 8-11 year olds. AA Foundation for Road Safety Research, England.

Faria, E. O. (2002) Bases para um programa de educação para o trânsito a partir do estudo de percepção de crianças e adolescentes. Tese de D.Sc., COPPE/UFRJ, Rio de Janeiro, RJ, Brasil.

Faria, E. O. e M. G. C. Braga (1999) “Educando crianças para o trânsito urbano com o computador: uma proposta de software educativo". In: Transporte em Transformação II: trabalhos vencedores do Prêmio CNT Produção Acadêmica 1997, cap. 1, p. 1-19. Makron Books \& Confederação Nacional do Transporte, São Paulo.

Faria, E. O. e M. G. C. Braga (2004) “Condições necessárias e objetivos da educação para o trânsito segundo o ponto de vista dos profissionais brasileiros da área". Artigo submetido ao XIII PANAM Conference of Traffic and Transportation Engineering. Rensselaer Polytechnic Institute, Albany, New York, EUA.

Freire, P. (1978) Educação como prática da liberdade (8 ${ }^{\mathrm{a}} \mathrm{ed}$ ). Paz e Terra, Rio de Janeiro.

Instituto Cultural Maurício de Souza (2004) Disponível em $<$ http://www.monica.com.br/institut/transito/ welcome.htm> Acesso em 11 jun. 2004

OCDE (1986) Recherche Routière: Efficacité des programmes d'éducation à la sécurité routière. Organisation de Coopération et de Développement Économiques, Paris.

Paraná (2004) Disponível em <http://www.pr.gov.br/detran/ educa/paranazinho/> Acesso em 11 jun. 2004.

Piaget, J. (1973) Estudos Sociológicos. Forense, Rio de Janeiro.

Reeves, T. C. e Hedberg, J. G. (2003) Interactive learning systems evaluation. Educational Technology Publications, New Jersey, USA.

SENAC (2004) Disponível em <http://www.mg.senac.br/ aprendendo/seguranca $>$ Acesso em 11 jun. 2004.

Weil, P. (1990) A Arte de Viver em Paz - por uma nova consciência e educação. UNESCO, Paris, França.

Eloir O. Faria (eloirfaria@oi.com.br) Marilita G. C. Braga (marilita@pet.coppe.ufrj.br) Gilda H. B. Campos (gilda@ccead.puc-rio.br) Artigo recebido em 8/12/2004 e aprovado em 16/07/2005. 